\title{
Predicting the number of children ever born using logistic regression model
}

\begin{abstract}
Modeling total children ever born is very crucial since Bangladesh is going under a rapid growth of population. We use logistic regression model, a well-known technique for categorical data analysis, to predict the number of children ever born using BDHS (2011) data. BDHS data is not random, since two stages stratified sampling is conducted to collect the data. Cluster correction and weight adjustment is necessary for analyzing this data. An extensive literature search fails to find any work which uses these adjustments for predicting the number of children ever born. In this paper these two adjustments have been used for predicting the number of children ever born. The prediction performance has been measured by training and test error.
\end{abstract}

Keywords: logistic regression model, Weight adjustment, cluster correction
Volume 3 Issue 4 - 2015

\author{
Ahshanul Haque,' Tofazzal Hossain, ${ }^{2}$ \\ Mohammed Nasser ${ }^{3}$ \\ 1,3 Department of Statistics, Rajshahi University, Bangladesh \\ 2Department of Statistics, Bangabandhu Sheikh Mujibur Rahman \\ Science and Technology University, Bangladesh
}

Correspondence: Tofazzal Hossain, Department of Statistics, Bangabandhu Sheikh Mujibur Rahman Science and Technology University, Gopalganj, Bangladesh, Email tofazzal.stat@gmail.com

Received: March 23, 2015 | Published: April 09, 2015
Abbreviations: BDHS, bangladesh demographic and health survey; NIPORT, national institute for population research and training; EA, enumeration areas

\section{Introduction}

The density of population in our country is $13^{\text {th }}$ in the world where 1118.65 persons live per square $\mathrm{km} .{ }^{1}$ As a result, we face several crises such as poor economic condition, lack of quality education, lack of good medical facilities, lack of improved accommodation, poverty etc. The Government of Bangladesh has coined two popular family planning slogans: Two is good enough-boy or girl and one child are good, but no more than two. We should control the population increase throw controlling the variable that influence growth rate. So it is important to model 'Total Children Ever Born' which represent potentiality of population growth.

Several works have been done using the variable 'Total Children Ever Born'. In, ${ }^{2}$ Negative Binomial Regression model and Generalized Poisson Regression model is compared for this variable. ${ }^{3}$ Shows the Effects of socio-demographic factors on children ever born for domestic and non-domestic violence. ${ }^{4}$ Examines the patterns and differentials of birth intervals of ever married women in Bangladesh. In the above mentioned articles, cluster correction and weight adjustment have not been adopted, although the data is collected under two stage stratified sampling. In this paper, we use logistic regression model making these adjustments for predicted the number of Children Ever Born and measure the prediction performance.

There are four sections in this paper. Section one introduces the problem whereas section two discusses data source, data nature, statistical technique that is used in this article. Section three presents results and discussion. Finally, section four concludes the findings.

\section{Methods and materials}

\section{Data description}

The study is based on secondary data. The sources of data are the Bangladesh Demographic and Health Survey (BDHS) - 2011. The BDHS-2011 data was conducted under the authority of the National Institute for Population Research and Training (NIPORT) of the
Ministry of Health and Family Welfare. It was implemented by Mitra and Associates, a Bangladeshi research firm located in Dhaka. The BDHS-2011 sample was stratified and selected in two stages. Each division was stratified into urban and rural areas. The urban areas of each division are further stratified into two strata: city corporations and other than city corporations. In the first stage, 600 Enumeration Areas (EA) were selected, with probability proportional to the EA size and with independent selection in each sampling stratum. In the second stage of selection, a fixed number 30 household per cluster was selected with an equal probability systematic selection from the newly created household listing.

With this design, the survey selected 18,000 residential households, and was expected to result in completed interviews with about 18,000 ever married women. In addition, ever-married men age 15-54 in every third household were eligible for the male survey. But for the sake of computational advantage without losing much information required to meet our objectives we consider women (40-49 years old) who reached the last stage of reproductive period in their lives. In this stage there were 2979 women with average (Median) 4 children ever born, which indicates that there is much need to decrease the target variable.

\section{Variables under study}

In the 2011 BDHS, a number of socio-economic and demographic variables are available. With help of descriptive plots of the data set as well as previous studies, ${ }^{5}$ we considered only seven explanatory variables namely fertility preference, same sex of first two children, age at first cohabitation, education of couple, religion, respondent currently working and food security which are found highly related to the response variable. The response variable 'Total Children Ever Born' has 22 categories which are $0,1 \ldots 21$. For our study purposes, we make only two categories 0 for the number of children two or less and 1 for more than two children. In the original data, there are variables for the sex of the children. Using this information we make the variable 'same sex of first two children' which has only two categories 0 for sex of first two children is not same and 1 for sex of first two children is same. The original data set has the variables husband's education and wife's education but the two variables are tending to collinear. To avoid multi collinearity problem, we make 
the variable 'education of couple' combining the two variables which has three categories 0 for at least one (husband or wife) is below SSC, 1 for both completed SSC and 2 for both completed HSC or above. No previous studies used the variable food security but we use here because this variable is highly related to the response variable.

\section{Logistic regression}

In logistic regression model, the dependent variable is categorical and the independent variable may either be categorical or continuous. The binary logistic regression model for the binary dependent variable $\mathrm{Y}$ and the independent variables $\mathrm{X}_{1}, \mathrm{X}_{2}, \ldots, \mathrm{X}_{\mathrm{r}}$ is given by

$$
\left.\mathrm{p}=\mathrm{P}\left(\mathrm{Y}=1 / \mathrm{X}_{1}, \mathrm{X}_{2}, \ldots, \mathrm{X}_{\mathrm{r}}\right)=\mathrm{e}^{(\beta 0+\beta 1 \mathrm{X} 1+\beta 2 \mathrm{X} 2+\cdots+\beta \mathrm{Xr} r}\right) /\left(1+\mathrm{e}^{\beta 0+\beta 1 \mathrm{X} 1+\beta 2 \mathrm{X} 2+\cdots+\beta \mathrm{Xr}}\right)
$$

The above relationship can be expressed alternatively in terms of $\log$ odds associated with $\mathrm{p}$ as follows:

$$
\log (\mathrm{p} / 1-\mathrm{p})=\beta_{0}+\beta_{1} \mathrm{X}_{1}+\beta_{2} \mathrm{X}_{2}+\cdots+\beta_{\mathrm{r}} \mathrm{X}_{\mathrm{r}}
$$

\section{Results and discussion}

First we show the proportions for our categorical study variables which are risk factors for the large family for all the BDHS data in Table 1.

\begin{tabular}{|c|c|c|c|c|c|c|}
\hline Variables & $1993-94$ & $1996-97$ & $1999-00$ & 2004 & 2007 & 2011 \\
\hline Number of children $>2$ & 94.53 & 92.56 & 89.63 & 88.87 & 84.4 & 80.08 \\
\hline \multicolumn{7}{|l|}{ Fertility preference } \\
\hline Have another & 2.51 & 2.34 & 2.26 & 2.36 & 2.9 & 3.44 \\
\hline Undecided & 0.76 & 1.01 & 0.24 & 0.26 & 0.21 & 0.19 \\
\hline No more & 61.63 & 55.92 & 65.77 & 61.88 & 69.01 & 82.54 \\
\hline Sterilized (respondent or partner) & 18.92 & 22.27 & 21.19 & 18.22 & $|5.2|$ & 13.83 \\
\hline Declared in fecund & 16.19 & 18.46 & 10.54 & 17.28 & 12.67 & \\
\hline Same sex of first two children & 48.47 & 44.7 I & 47.79 & 47.22 & $46.8 \mathrm{I}$ & 45.03 \\
\hline \multicolumn{7}{|l|}{ Couples education } \\
\hline at least one is below SSC & 95.44 & 95.31 & 91.19 & 91.45 & 90.35 & 87.48 \\
\hline Both are SSC Complete & 3.17 & 3.23 & 5.09 & 5.58 & 5.7 & 8.27 \\
\hline Both are HSC Complete and above & 1.39 & 1.45 & 3.73 & 2.97 & 3.95 & 4.25 \\
\hline Religion (Islam) & 84.87 & 86.74 & 82.75 & 87.57 & 89.7 & 86.82 \\
\hline Respondent currently working (yes) & 15.52 & 39.25 & 23.79 & 24.91 & 31.64 & 14.63 \\
\hline \multicolumn{7}{|l|}{ Food Security } \\
\hline Secure & & & & & & 62.75 \\
\hline Insecure & & & & & & 37.25 \\
\hline
\end{tabular}

Table I Proportions of our categorical study variables for different BDHS data

From Table 1, we observed that the families with greater than two children are decreasing over time. For the fertility preference variable the proportion of the category 'no more' is highest and increasing day by day. That is people are being aware of keeping family size small. For the variable 'couples education', the proportion of the categories 'both completed SSC' and 'both completed HSC' are increasing over time. IT indicates that the education rate is increasing over time. For the variable 'respondent currently working', the proportion is sometimes increasing and sometimes decreasing and in 2011 it has fallen down. One of the reasons may be that people are being educated but they are not getting jobs. The results of the logistic regression model for predicting the total children ever born are given in Table 2. 
Table 2 Results of logistic regression model

\begin{tabular}{|c|c|c|c|c|c|}
\hline Predictor Variables & Odds Ratio & Std. Err. & t-test & p-value & $95 \% \mathrm{Cl}$ of $\mathrm{OR}$ \\
\hline \multicolumn{6}{|l|}{ Fertility preference } \\
\hline No more & Reference & & & & \\
\hline Have another & 0.08 & 0.03 & -7.58 & 0.00 & $0.04-0.16$ \\
\hline Undecided & 19.37 & 23.34 & 2.46 & 0.01 & I.82-206.54 \\
\hline Sterilized (respondent or partner) & 0.68 & 0.12 & -2.20 & 0.03 & $0.478-0.96$ \\
\hline Declared in fecund & 0.62 & 0.12 & -2.49 & 0.01 & $0.43-0.90$ \\
\hline \multicolumn{6}{|l|}{ Sex of first two children } \\
\hline Different sex of first two children & Reference & & & & \\
\hline Same sex of first two children & 1.54 & 0.19 & 3.62 & 0.00 & $1.22-1.95$ \\
\hline Age at first cohabitation & 0.87 & 0.02 & -6.53 & 0.00 & $0.83-0.90$ \\
\hline \multicolumn{6}{|c|}{ Education level of husband and wife } \\
\hline Husband or Wife is below SSC & Reference & & & & \\
\hline Both are completed SSC & 0.68 & 0.13 & -1.95 & 0.05 & $0.46-1.00$ \\
\hline Bothe are HSC or above & 0.24 & 0.06 & -5.31 & 0.00 & $0.14-0.41$ \\
\hline \multicolumn{6}{|l|}{ Religion } \\
\hline Others & Reference & & & & \\
\hline Islam & 1.53 & 0.25 & 2.60 & 0.01 & $1 . \mid 1-2.11$ \\
\hline \multicolumn{6}{|l|}{ Respondent currently working } \\
\hline No & Reference & & & & \\
\hline Yes & 0.46 & 0.08 & -4.75 & 0.00 & $0.33-0.63$ \\
\hline \multicolumn{6}{|l|}{ Food security } \\
\hline Secure & Reference & & & & \\
\hline Insecure & 1.38 & 0.17 & 2.62 & 0.01 & I.08-I.76 \\
\hline
\end{tabular}

From the Table 2 it is observed that all the predictors have statistically significant effect on the response variable ('Total children ever born'). Women with fertility preference undecided are 19.37 time more likely to have more than two children than those with fertility preference no more. Families with the same sex of first two children are 1.54 times more likely to have more than two children than families with different sex of first two children. Families with both husband and wife completed SSC are $32 \%$ less likely to have more than two children than those with at least one (husband, wife or both) are below SSC. Again families with both husband and wife completed HSC or above are $76 \%$ less likely to have more than two children than those with at least one (husband, wife or both) are below SSC. Muslim families are 1.53 times more likely to have more than two children than non-Muslim families. Working women are 54\% less likely to have more than two children than non-working women. Families of unsecured in food are 1.38 times more likely to have more than two children than families of secured in food.
The variable fertility preference has greatest influence on having more than two children. So to keep family size small it is necessary to convert families with fertility preference "undecided" to "no more". Public awareness should be raised about the fact that sex of children is no matter. From the expectation of male child, family size is being increased. Educated couple keeps their family size small. Thus education rate should be increased. People should be employed because working people keep family size small. Food security should be maintained for all families because to ensure food security people want more children with an expectation of increasing earning members of family.

To measure the prediction performance of the model we randomly divide the whole data set into two parts: training data and test data. The training data set contains of $75 \%$ and the test data set contains $25 \%$ of the whole data set. Using the $75 \%$ data we fit the model and calculate the misclassification error which is called training error. Again using the fitted model we predict the outcomes for the $25 \%$ 
data and calculate the misclassification error which is called test error These errors are given in Table 3 .

Table 3 Approximate misclassification error for training (75\%) data and test (25\%) data

\section{Misclassification Error}

\begin{tabular}{ll}
\hline Training Error & $15.42 \%$ \\
Test Error & $17.90 \%$ \\
\hline
\end{tabular}

\section{Conclusion}

Cluster correction is necessary for BDHS data since the data are collected under two stage stratified sampling. The prediction performance of the logistic regression model is quite reliable after cluster correction since the training and test errors are approximately 15.42 and 17.90 respectively. From our analysis we can conclude that to keep family size small the government should take necessary steps to raise the awareness of the people to have fertility preference "no more", not to differentiate male and female child. Again government should take steps to increase the education rate of the people, to increase the employment rate and to ensure the food security of the people.

\section{Acknowledgement}

None.

\section{Conflict of interest}

None.

\section{References}

1. CIA World Factbook. 2012.

2. Sadia Farhana. Performance of generalized poisson regression model and negative binomial regression model in case of over-dispersion count data. International Journal of Emerging Technologies in Computational and Applied Sciences (IJETCAS). 2013:558-563.

3. Islam R, Alam R, Islam RB. Effects of socio-demographic factors on children ever born for domestic and non-domestic violence: Application of Path model. Global Advanced Research Journal of Social Science (GARJSS). 2013;2(2):38-46.

4. Chowdhury AH, Karim A. Patterns and differentials of birth intervals in Bangladesh. The Global Journal of Science Frontier Research. 2013;13(2).

5. Nicholas P Jewell. Statistics for epidemiology, chapman and hall. texts in statistical science. 2003

6. Bursac Z, Gauss CH, Williams DK, et al. Purposeful selection of variables in logistic regression. Source Code Biol Med. 2008;3:17.

7. Hosmer DW, Lemeshow S, Sturdivant RX. Applied logistic regression New York: Wiley; 2000

8. Agresti A. Categorical data analysis. 2nd ed. New Jersely: John Wiley and Sons; 2002.

9. Aldrich JH, NelsonFD. Linear probability, logit, and probit models. Thousand Oaks, CA: Sage; 1984.

10. Thomas Lumley. Complex surveys: a guide to analysis using R. John Wiley \&Sons, Inc.; 2011.

11. Tibshirani R, Walther G, Hastie T. Estimating the number of clusters in a data set via the gap statistic. Journal of the Royal Statistical Society B. 2001;63(2):411-423. 